\title{
International \\ Orthopaedics
}

(C) Springer-Verlag 1998

\section{Predicting the outcome of adductor tenotomy}

\author{
J. Cottalorda ${ }^{1}$, V. Gautheron ${ }^{2}$, G. Metton ${ }^{2}$, E. Charmet ${ }^{2}$, K. Maatougui ${ }^{1}$, Y. Chavrier ${ }^{1}$ \\ ${ }^{1}$ Orthopaedic Pediatric Surgery Department, University Hospital of Saint-Etienne, France \\ 2 Physical Medicine and Rehabilitation Department, University Hospital of Saint-Etienne, France
}

Accepted: 26 March 1998

Summary. This study reviewed 57 hips in 30 children (18 girls and 12 boys) with cerebral palsy who had undergone an adductor tenotomy alone or in combination with an anterior obturator neurectomy (23 hips). Results were evaluated by the Reimers migration percentage $(M P)$. The hips were split into three groups: group A (12 hips) a preoperative MP of less than 20\%, group $B$ (25 hips) between 20 and $40 \%$, and group $C$ (20 hips) more than $40 \%$. The mean age at the time of surgery was 6 years and 1 month (range: 2.5-13 years). The mean period of review was 6 years and 3 months (2-20 years). The results were considered as "good" when radiographs at the longest follow-up showed a decrease of $>10 \%$ of the MP, as "bad" when they showed an increase of $>10 \%$, and as "stable" when the MPs varied less than $10 \%$. At the latest review of group A, 11 were stable (92\%) and 1 was bad. In group B, 12 were stable $(48 \%), 7$ were good $(28 \%)$, and 6 were bad (24\%). In group C, 7 were stable (35\%), and 13 were bad (65\%). The preoperative migration percentage proved to be the only predictor of outcome. Age at the time of surgery had no constant significant effect on the outcome, neither had the addition of an anterior neurectomy.

Résumé. 57 ténotomies des adducteurs ont été réalisées chez 30 enfants IMC tétraparétiques spastiques. A 23 reprises, une neurotomie obturatrice a été associée au geste de ténotomie. Le recul moyen était de 6 ans et 3 mois (2A-20A). Nous avons jugé nos résultats avec l'indice de Reimers et établi 3 groupes selon sa valeur. Cet indice était inférieur à $20 \%$ dans le groupe A (2 hanches), comp-

Reprint requests to: J. Cottalorda, Service de chirurgie infantile, Hôpital Nord, 42055 Saint-Etienne Cedex 2, France Tel.: 33-4-7782-8037; fax: 33-4-7782-8465 ris entre 20 et $40 \%$ dans le groupe $B$ (25 hanches), et supérieur à $40 \%$ dans le groupe C (20 hanches). Au plus long recul une nouvelle analyse de cet indice a été réalisée. On a considéré qu'il avait amélioration quand l'indice avait diminué de $10 \%$ par rapport aux clichés pré-opératoires, aggravation quand il avait augmenté de $10 \%$ et stabilisation quand sa variation était comprise entre -10 et $+10 \%$. Dans le groupe A, 11 hanches se sont stabilisées (92\%) et 1 s'est aggravée. Dans le groupe B, 12 hanches se sont stabilisées (48\%), 7 se sont améliorées (28\%) et 6 se sont aggravées (24\%). Dans le groupe C, 7 hanches se sont stabilisées (35\%), 13 se sont aggravées $(65 \%)$ et aucune ne s'est améliorée. En conclusion le facteur prédictif essentiel reste l'indice de Reimers. L'âge de l'enfant au moment de l'intervention ne semble pas influer de manière évidente sur le résultat final, pas plus que l'association d'une neurotomie obturatrice.

\section{Introduction}

Adduction is the most common hip deformity in cerebral palsy (CP) [24]. In those who are severely affected and unable to walk, it gradually but inexorably leads to subluxation and subsequent dislocation, with disastrous functional consequences [12, 19, 23]. Hip dislocation results in difficulty in sitting, pain, and perineal care problems [14, 22].

Many factors contribute to subluxation and dislocation of the hip, such as coxa valga, pelvic obliquity, and shallowness of the acetabulum due to the absence of weight-bearing $[3,14,22]$. The main factor, however, is muscle imbalance, which produces adduction and flexion deformities, shifting the axis of rotation of the hip towards the lesser trochanter and decreasing femoral head coverage $[8,14,22]$. 
Adductor tenotomy has been a standard surgical procedure for many years, with or without obturator nerve neurectomy, as a preventive procedure $[7,14$, $21,24]$. There is no consensus regarding the nature of soft-tissue surgery, the optimum age of the child at operation, and the degree of hip subluxation that can be treated successfully by this methods [7].

The aims of this retrospective study were to analyze the results of adductor tenotomies in children with $\mathrm{CP}$, to assess their radiographic outcome and to determine whether age at the time of surgery, the addition of an anterior neurectomy, and the preoperative radiographic migration percentage were reliable predictors of outcome.

\section{Material and method}

This is a retrospective study of children who underwent adductor tenotomy. All had spastic quadriplegic-pattern involvement; 27 were nonambulant, and 3 were able to walk occasionaly with assistance. Cases without adequate radiographic review and patients with concomitant bone surgery or surgery on the hamstrings or the psoas were excluded from this study A 2-year minimum follow-up was thought to be necessary for measurable changes in the migration percentage of the hips. The final study group was of 57 hips in 30 children (18 girls and 12 boys) operated on in our hospital between 1977 and 1995. Three patients had a unilateral procedure to correct an asymmetric involvement. The preoperative passive adduction averaged $27^{\circ}$ (range: $10-40^{\circ}$ ) with the hip in flexion. Fixed pelvic obliquity was present in 6 children, and scoliosis in 8 .

For radiological analysis we used the acetabular index and the migration percentage. The acetabular index defined preoperatively is the angle between Hilgenreiner's line and the line joining the lateral and medial margins of the acetabulum. The stability of the hip was evaluated by the migration percentage (MP) indice (Fig. 1), as measured on the preoperative and last available follow-up radiographs. This indice is described by Reimers [16] as the ratio of the width of the upper femoral epiphysis to that part uncovered. Radiographs were taken with the child relaxed and supine, with the lower limbs parallel and in neutral rotation.

The hips were divided into three groups: group A (12 hips; mean age: 6 years) had a preoperative MP of less than $20 \%$ (preoperative acetabular index ranged from $7-18^{\circ}$ with a mean value of $11^{\circ}$ ), group B (25 hips; mean age: 6 years and 4 months) had a preoperative MP between 20 and $40 \%$ (preoperative acetabular index ranged from $13-29^{\circ}$ with a mean value of $18^{\circ}$ ), and group C (20 hips; mean age: 6 years and 1 month) a preoperative MP of more than $40 \%$ (preoperative acetabular index ranged from $17-44^{\circ}$ with a mean value of $31^{\circ}$ ). The mean age at the time of surgery was 6 years and 1 month (range: $2.5-13$ years)

The adductor longus was always completely transected, by open procedure in 54 cases and by percutaneously in 3 . The fascia of the gracilis was opened and a complete myotomy was performed in 34 cases. Occasionally, portions of the adductor brevis were sectioned if necessary to obtain abduction to at least $40^{\circ}$. Partial anterior obturator neurectomy was performed in 23 cases. The 3 unilateral tenotomies were carned out at the age of 4 (MP of 22\%), 5 (MP of $41 \%$ ), and 8 (MP of 39\%). There was no pelvic obliquity in these children.

After surgery, all children were immobilized for 3 weeks in an abduction hip spica cast. Then, night splinting with an abduction splint was continued for 3 months or more.

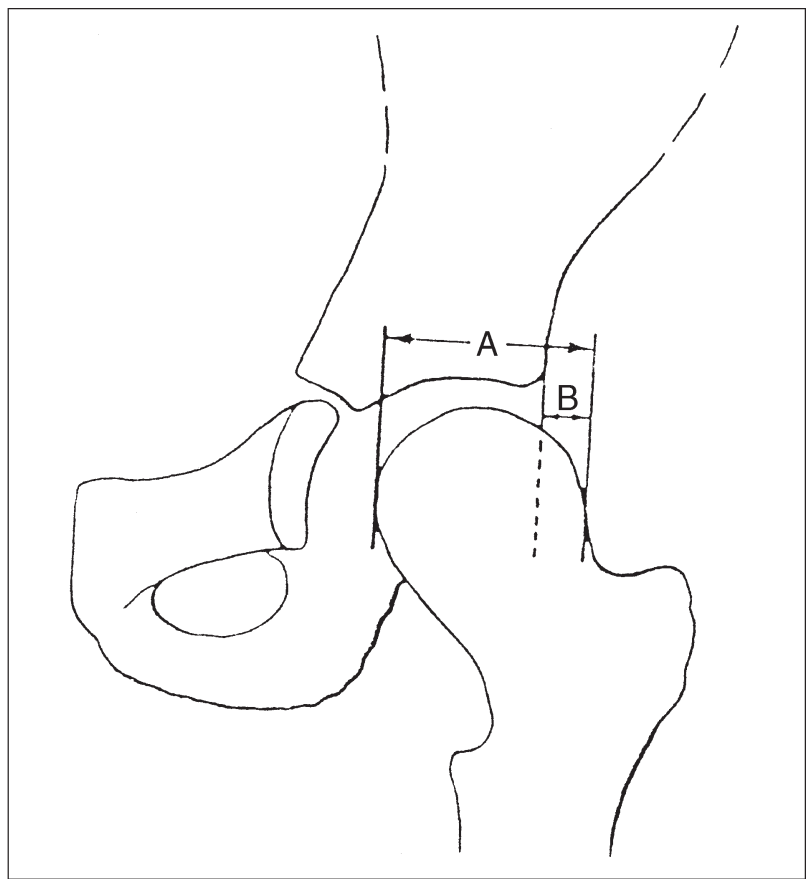

Fig. 1. The migration percentage is the amount of uncovered head (distance B) divided by the total head width (distance A) multiplied by 100

\section{Statistical study}

All results were subjected to statistical analysis. Differences between the age of children at surgery, sex, and mean follow-up for the three groups were assessed by several analyses of variance (ANOVAs) and by the post hoc test of Scheffe. To determine statistically the MP evolution with or without anterior neurectomy, we used a $\chi^{2}$ test. A significance level of $P<0.05$ was assigned.

\section{Results}

\section{Clinical results}

The three groups were statistically similar with regard to sex, age, and follow-up. The average improvement of hip abduction at operation was $34^{\circ}$ (range: $15-50^{\circ}$ ). There were three haematomas which resolved satisfactorily in a few days.

The mean period of review was 6 years and 3 months (range: $2-20$ years). The mean age at followup was 12 years and 3 months in group A (range: 9-18 years), 11 years and 10 months in group B (range: 6-25 years), and 12 years and 4 months in group C (range: 5-22 years). At follow-up the average hip abduction was $39^{\circ}$ (range: $15-60^{\circ}$ ) with the hip in flexion. No overcorrection with abduction contracture was observed. Pelvic obliquity was present in 13 children, and scoliosis in 14.

For the 3 unilateral tenotomies (average follow-up: 4 years and 7 months) the abduction was symmetrical and there was no pelvic obliquity. 


\section{Radiographic analysis}

The results were considered as "good" when radiographs at the longest follow up showed a decrease of $>10 \%$ of the MP, as "bad" when they showed an increase of $>10 \%$ and as "stable" when the MP varied by $<10 \%$. At the latest review of group A, 11 were good (92\%), and 1 was bad. In group B, 12 were stable (48\%), 7 were good $(28 \%)$ and 6 were bad (24\%). In group C, 7 were stable (34\%), and 13 were bad (65\%). We found no significant difference in length of follow up for the three groups and this did not influence the result. We also verified statistically, in each group, whether the follow up results were better in children operated on at a younger age than in those who were older. Age at the time of surgery did not have a significant affect on the outcome, except in group B, where the mean age was 8 years and three months for the good results, 6 years and five months for the stable and four years and one month for those who were poor. An anterior neurectomy did not significantly affect the results and there was no improvement when the pre-operative acetabular index was over $33^{\circ}$.

For the three unilateral tenotomies, the migration percentage was stabilised at the longest follow-up, and we noted no negative influence on the opposite hip. Thirteen children needed a further operation including adductor tenotomy (5 cases), varus intertrochanteric femoral osteotomy (7 cases) and pelvic osteotomy ( 8 cases). In these children, the results were considered as bad, and the latest follow-up was calculated as the time between the two operations.

\section{Discussion}

Theoretically, dislocation of the hip in children with CP should be preventable by proper containment [17]. However, it is not always possible to prevent some of these deformities by such means and surgery may be necessary [17]. The incidence of dislocation of the hip in patients with severe $\mathrm{CP}$ is between $60 \%$ and $80 \%$ [10, $12,15]$. It has also been shown that as many as $50 \%$ of these dislocated hips become painful $[1,6]$. Maintaining the hips in the reduced position by soft tissue surgery is of significant importance [22]. Before dislocation occurs, and adductor myotomy, with or without obturator neurectomy, will be effective in reducing spasticity, contracture or both [17]. Many reports have confirmed the effectiveness of this procedure $[2,13,14]$.

\section{Clinical analysis}

Sharred et al. [20] advised that initial surgical intervention should be considered whenever the range of abduction was less than $45^{\circ}$. The average hip abduction at follow-up was $39^{\circ}$ whereas it was $27^{\circ}$ before operation, with an average improvement during operation of $34^{\circ}$. There was a decrease of $22^{\circ}$ compared with that obtained during operation. Moreau et al.
[14] found that patients had lost approximately one half of the abduction obtained at surgery at five year follow-up. A range of abduction of under $30^{\circ}$ is a good indication for an adductor tenotomy, even before radiological signs appear, and will help to prevent possible migration of the femoral head.

\section{Migration percentage and acetabular index}

In our study, we noted the migration percentage and the acetabular index before operation, but used the migration percentage to assess results because this measurement is easier to determine than the acetabular index. That is often difficult to assess on plain radiographs [7] and is significantly affected by pelvic tilt [18], which may make for inaccuracy and difficulty in comparing one radiographic examination to another. It is more useful when considering whether to perform soft tissue or bony surgery in children with $\mathrm{CP}$ [7], and will give a rough estimate of hip displacement and acetabular depth [23].

Others have reported that the acetabular index was not a significant predictor [7, 24]. Cornell et al. [7] thought that the preoperative acetabular index was not a significant predictor of the final migration percentage, but there was a close association between the migration percentage and the acetabular index before operation. They noticed that soft tissue operations were unsuccessful in 13 hips out of 15 with a per-operative acetabular index of over $27^{\circ}$. We found no improvement when this index was $>30^{\circ}$.

Vidal et al. [23] showed that the linear progression of the migration percentage increased from an early age and could be measured by the age of 12 months. The values of the angles of acetabular obliquity were not changed compared with normal values in children of the same age until after the age of 30 months. They therefore felt that acetabular obliquity could not be related to the future development of the hip because there was no relationship between the migration percentage and acetabular obliquity before this age. Acetabular obliquity only appeared when the migration index was about $20 \%$ [23].

The migration percentage has a recognised error of measurement of $+/-10 \%[13,18]$. In order to eliminate this, we considered it a good result if the MP improved by $>10 \%$ at follow-up.

\section{Radiographic analysis}

Our children fell into three broad groups. Most of the hips (11 out of 12) with a pre-operative migration percentage of $<20 \%$ (group A) were stabilised. There was no good result in this group, because we chose a decrease of MP $>10 \%$ as the criterion for this, and these hips were unlikely to decrease by more than $10 \%$. When the migration percentage is more that $40 \%$ (group C), it is possible to have radiographic stability without any improvement. For 

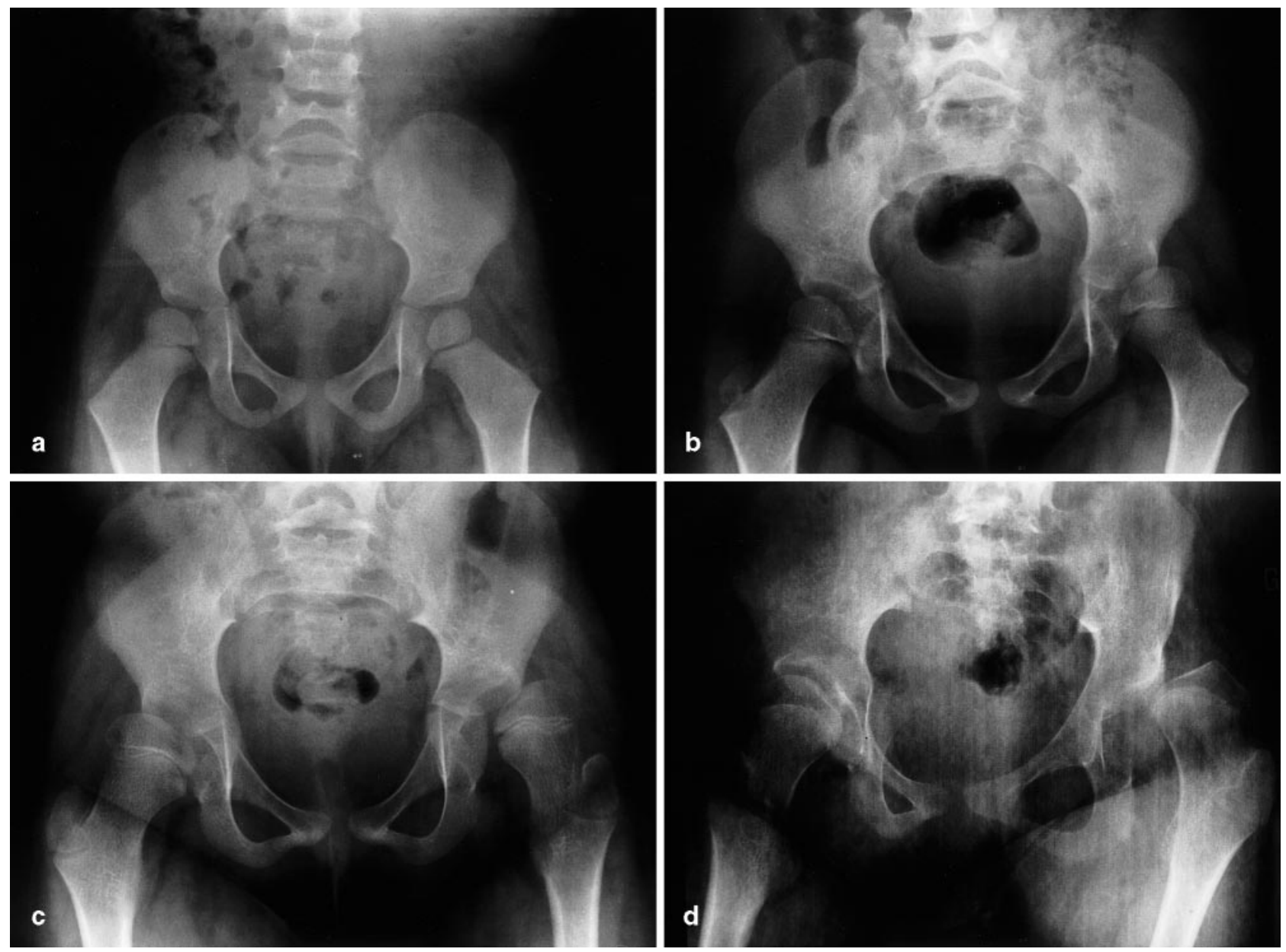

Fig. 2a-d. Radiographic evolution of hips in a spastic quadriplegic child. Note that the hips were normal at the age of 2 (a) and that they inexorably lead to subluxation (b and $\mathbf{c}$ ) and dislocation (d). This child has been operated on at the age of 6 (c)

hips with a migration percentage of only $20-40 \%$ (group B), it is possible to obtain improvement or stabilisation but the long term result may sometimes be unfavourable.

We decided to operate on some children with an MP under $20 \%$ because their range of abduction seemed too limited, though some authors think that in these cases surgery makes no difference [19]. It is important to take the migration rate into account, because it is related to the severity of neurological involvement, and the higher it is, the earlier dislocation will occur. Cornell et al. [7] found that most of the hips with a pre-operative migration percentage of $<40 \%$ had a satisfactory result, whereas all hips with a value of more than $60 \%$ had an unsatisfactory outcome. For hips with a migration percentage in the range of $40-60 \%$, soft tissue surgery was most successful if adequate bracing was obtained after operation. Our results are not as good as those of Cornell et al. and resemble those of Miller et al. [13]. They found that mature hips whose migration percentage remained $<25 \%$ would remain permanently normal. Those with a migration of $25 \%-40 \%$ have a more un- with a bilateral adductor release, but it was too late because the migration percentage was too high. A varus intertrochanteric femoral osteotomy had to be performed secondarily

certain outcome, and those with an MP $>40 \%$ are not likely to become normal without further operation. We agree with Moreau [14] and Silver et al. [21] that when the subluxation is about $50 \%$, and the acetabular index is more than $30^{\circ}$, a varus intertrochanteric femoral osteotomy or a pelvic osteotomy should be performed, because soft tissue releases will not be effective in controlling subluxation (Fig. 2). Onimus et al. [15] felt that surgery performed on hips with an MP $>30 \%$ should not be considered preventive: soft tissue release can only decrease or stabilise the rate of migration of the hip. A number of results rated good may be considered as failures, since partial improvement of the MP leads to persistent subluxation, which eventually requires further operation. Samilson et al. [17] and Vidal et al. [23] noted that adductor myotomy is valueless once dislocated occurred.

\section{Age at time of operation}

In contrast to the findings of some authors $[15,16$, $20,23]$, but not of others $[7,9,18,21,24]$, we found 
that the age of patients at the time of operation was not a significant predictor of outcome, except in group B. In this group, the older the children the better were the results, probably because hips of the youngest children had the greatest potential for evolution. It is very important to analyse the results of tenotomies according to the age of the patient at the time of operation when compared with the MP. Many reports are unclear about this [9, 18, 21, 24]. Children with a small MP, operated on when young, will probably have better results than those with a greater MP operated on later. Also, in the younger child, acetabular growth and remodelling have much more influence on outcome than in a ten-year-old.

\section{Obturator neurectomy}

It has been shown previously that the addition of anterior neurectomy does not significant improve results $[7,9]$. We confirmed this. Miller [13] added an anterior branch obturator neurectomy in order to attempt to balance asymmetric spasticity around the hips in children who were very spastic and could not walk. However, anterior branch obturator neurectomy should be avoided in children who can walk because of the potential for wide based gait and hyperabduction [13].

\section{Unilateral tenotomies}

Reimers [16], Samilson et al. [17] and Silver et al. [21] have warned that unilateral adductor tenotomy has a negative influence on the opposite side. Carr and Gage [4], with the same average follow up as ourselves, noticed that unilateral soft tissue procedures on children under the age of 9 had an untoward effect on the opposite hip, leading to pregressive subluxation and the development of a wind-swept deformity. We did not see this in our three cases.

\section{Comparison with other results in the literature}

Howard et al. [10], studied the natural history of spontaneous dislocation of the hip in CP. They noted that in quadriplegic patients, the incidence of dislocation was very high $(59 \%)$, whereas in those with diplegia, only $6.5 \%$ were affected. They found no evidence of dysplasia or instability of the hip in any patients with unilateral hemiplegia. Reports concerning the prevention of hip dislocation by soft tissue surgery are often confusing, because they included both quadriplegic, diplegic and sometimes hemiplegic children $[2,5,7,9,13,14,16-18,20,22-24]$. This may explain whey our results are less optimistic than those of most other series.

Some authors $[11,14,15,22]$ have reported that adductor tenotomy associated with surgical release prevents hip subluxation. However, Houkom et al. [9] and Silver [21] did not find this. A comparison with our results and those reported by others was also hampered by different interpretations of a "good outcome", and because other studies often combined different procedures $[17,20]$.

\section{Management of the hip in $C P$}

We agree with Vidal et al. [23] that musculotendinous releases are effective in recentring the femoral head early, but not in correcting dysplasia. It is preferable to anticipate its development by early tenotomies, which are much better tolerated than pelvic osteotomy. Onimus et al. [15] suggested that successful results were obtained in $90 \%$ of children under the age of four with a MP <33\%. However, like Miller et al. [13], we think that it is possible to use soft tissue release for severe subluxation in children who are younger than four years. This is a relatively minor procedure compared with a bony reconstruction, and some hips can be stabilised, allowing the child several years of growth. This allows reconstructive surgery to be postponed until the child is older and has better bone stock [13].

\section{References}

1. Bagg MR, Farber J, Miller F (1993) Long-term follow-up of hip subluxation in cerebral palsy patients. J Pediatr Orthop 13:32-36

2. Banks HH, Green WT (1960) Adductor myotomy and obturator neurectomy for the correction of adduction contracture of the hip in cerebral palsy. J Bone Joint Surg [Am] 42:111-126

3. Black BE, Griffin PP (1997) The cerebral palsied hip. Clin Orthop 338:42-51

4. Carr C, Gage JR (1987) The fate of nonoperated hip in cerebral palsy. J Pediatr Orthop 7:262-267

5. Cooke PH, Cole WG, Carey RP (1989) Dislocation of the hip in cerebral palsy: natural history and predictability. J Bone Joint Surg [Br] 71:441-446

6. Coopperman DR (1987) Hip dislocation in spastic cerebral palsy: long term consequences. J Pediatr Orthop 7:268-276

7. Cornell MS, Hatrick NC, Boyd R, Baird G, Spencer JD (1997) The hip in children with cerebral palsy: prediction of the outcome of soft tissue surgery. Clin Orthop 340:165-171

8. Hoffer MM (1986) Management of the hip in cerebral palsy. J Bone Joint Surg [Am] 68:629-631

9. Houkom JA, Roach JW, Wenger DR, Speck G, Herring JA, Norris EN (1986) Treatment of acquired hip subluxation in cerebral palsy. J Pediatr Orthop 6:285-290

10. Howard CB, McKibbin B, Williams LA, Mackie I (1985) Factors affecting the incidence of hip dislocation in cerebral palsy. J Bone Joint Surg [Br] 67:530-532

11. Kalen V, Bleck EE (1985) Prevention of spastic paralytic dislocation of the hip. Dev Med Child Neurol 27:17-24

12. Lonstein JE, Beck K (1986) Hip dislocation and subluxation in cerebral palsy. J Pediatr Orthop 6:521-526

13. Miller F, Dias RC, Dabney KW, Lipton GE, Triana M (1997) Soft-tissue release for spastic hip subluxation in cerebral palsy. J Pediatr Orthop 17:571-584

14. Moreau M, Cook PC, Ashton B (1995) Adductor and psoas release for subluxation of the hip in children with spastic cerebral palsy. J Pediatr Orthop 15:672-676

15. Onimus M, Allamel G, Manzone P, Laurain JM (1991) Prevention of hip dislocation in cerebral palsy by psoas and adductors tenotomies. J Pediatr Orthop 11:432-435 
16. Reimers J (1980) The stability of the hip in children: a radiological study of the results of muscle surgery in cerebral palsy. Acta Orthop Scand [Suppl] 184:1-100

17. Samilson RL, Tson P, Aamoth G, Green WM (1972) Dislocation and subluxation of the hip in cerebral palsy. $\mathrm{J}$ Bone Joint Surg [Am] 54:863-873

18. Schultz RS, Chamberlain SE, Stevens PM (1984) Radiographic comparison of adductor procedures in cerebral palsied children. J Pediatr Orthop 4:741-744

19. Scrutton D, Baird G (1993) Hip dysplasia in cerebral palsy. Dev Med Child Neurol 35:1028-1030
20. Sharrard WJW, Allen JMH, Heaney SH (1975) Surgical prophylaxis of subluxation and dislocation of the hip in cerebral palsy. J Bone Joint Surg [Br] 57:160-166

21. Silver RL, Rang M, Chan J, De La Garza J (1985) Adductor release in nonambulant children with cerebral palsy. J Pediatr Orthop 5:672-677

22. Spruit M, Fabry G (1997) Psoas and adductor release in children. Acta Orthop Belg 63:91-93

23. Vidal J, Deguillaume P, Vidal M (1985) The anatomy of the dysplastic hip in cerebral palsy related to prognosis and treatment. Int Orthop 9:105-110

24. Wheeler ME, Weinstein SL (1984) Adductor tenotomy: obturator neurectomy. J Pediatr Orthop 4:48-51 